\title{
Công tác đào tạo, bồi dưỡng cán bộ, công chức trong bối cảnh cuộc cách mạng công nghiệp lần thứ tư
}

\author{
Hoàng Mai \\ Học viện Hành chính Quốc gia, 77 Nguyễn Chí Thanh, Láng Hạ, Đống Đa, Hà Nội, Việt Nam \\ Nhận ngày 25 tháng 7 năm 2017 \\ Chỉnh sửa ngày 11 tháng 9 năm 2017; Chấp nhận đăng ngày 28 tháng 9 năm 2017
}

\begin{abstract}
Tóm tắt: Trong bối cảnh cuộc cách mạng công nghiệp lần thứ tư, năng lực quản trị nhà nước cần được nâng tầm để thích ứng. Điều này đòi hỏi công tác đào tạo, bồi dưỡng cán bộ, công chức cần phải đổi mới, phải thực sự là công cụ phát triển năng lực cho cán bộ, công chức. Do đó, hoạt động đào tạo, bồi dưỡng cán bộ, công chức cần được đổi mới cả về nội dung chương trình, phương thức tổ chức khóa bồi dưỡng để bảo đảm năng lực của đội ngũ cán bộ, công chức thực sự được nâng lên, đáp ứng yêu cầu quản lý nhà nước trong giai đoạn mới. Bài viết này phân tích những thách thức đặt ra trong cuộc cách mạng công nghiệp lần thứ tư đối với đào tạo, bồi dưỡng cán bộ, công chức và đề xuất một số giải pháp đổi mới đào tạo, bồi dưỡng cán bộ, công chức.
\end{abstract}

Tù khoá: Đào tạo, bồi dưỡng cán bộ, công chức, cuộc cách mạng công nghiệp lần thứ tư.

\section{Cách mạng công nghiệp lần thứ tư và công tác đào tạo, bồi dưỡng cán bộ, công chức}

Thế giới đã trải qua 4 cuộc cách mạng công nghiệp, bắt đầu bằng cuộc cách mạng công nghiệp lần thứ nhất với sự ra đời của đầu máy hơi nước. Cuộc cách mạng công nghiệp lần thứ hai diễn ra vào nửa cuối thế kỷ XIX với thay đổi từ sản xuất đơn lẻ sang sản xuất hàng loạt bằng máy móc vận hành với năng lượng điện. Cuộc cách mạng công nghiệp lần thứ ba diễn ra từ những năm 1970 với sự ra đời của sản xuất tự động dựa vào máy tính và thiết bị điện tử, máy tính cá nhân và mạng internet. Cuộc cách mạng công nghiệp lần thứ tư bắt đầu từ vài năm gần đây. Đó là cuộc cách mạng về sản xuất thông minh dựa trên các thành tựu đột phá

\footnotetext{
*ĐT.: 84-989099008.

Email: hoangmainapa@yahoo.com

https://doi.org/10.25073/2588-1116/vnupam.4115
}

trong các lĩnh vực công nghệ thông tin, công nghệ sinh học, công nghệ nano... với nền tảng là các đột phá của công nghệ số, vạn vật kết nối (Internet of things -IoT), các hệ thống liên kết giữa thế giới thực và thế giới ảo [1].

Cuộc cách mạng công nghiệp lần thứ tư đem đến những thay đổi to lớn trong mọi lĩnh vực của đời sống kinh tế - xã hội từ các mối quan hệ cá nhân đến các hoạt động ở tầm quốc gia, khu vực và toàn cầu. Báo cáo của Diễn đàn Kinh tế thế giới 2016 cũng chỉ ra 9 lĩnh vực chịu ảnh hương mạnh mẽ nhất của cách mạng công nghiệp lần thứ 4 bao gồm bán lẻ; các nhà máy sản xuất; ngành công nghiệp sản xuất phương tiện vận chuyển; nhà ở; văn phòng; nơi làm việc; các thành phố; môi trường sống và đặc biệt đó là yêu cầu về năng lực của nguồn nhân lực - một yếu tố đầu vào của quá trình sản xuất [2]. 
Đối với giáo dục và đào tạo, cuộc cách mạng công nghiệp lần thứ tư đặt ra đòi hỏi lớn về khả năng chuyển tải các tri thức mới, cập nhật kiến thức mới cho người học, khả năng phát triển nguồn nhân lực có năng lực đáp ứng đòi hỏi của thị trường lao động hiện tại và tương lai. Với áp lực của thị trường lao động nơi mà những việc làm cũ sẽ bị mất đi, thay thế bằng các thiết bị tự động, bằng trí tuệ nhân tạo, giáo dục và đào tạo cần phải là khởi nguồn để tạo ra và truyền tải những tri thức mới, phát triển nguồn nhân lực 4.0 đáp ứng yêu cầu thực tiễn, đồng thời cập nhật kiến thức mới cho nhân lực hiện tại để họ không trở thành những người đứng bên lề của cuộc cách mạng công nghiệp lần thứ tư hoặc bị ảnh hưởng tiêu cực từ cuộc cách mạng công nghiệp này. Hệ thống giáo dục mỗi quốc gia cần đổi mới để có thể tạo ra những nguồn nhân lực có năng lực vượt trội, có năng lực chuyên môn, có khả năng làm việc với công nghệ thông minh, có kỹ năng sống và giao tiếp quốc tế, khả năng kết nối và chia sẻ.

Cuộc cách mạng công nghiệp lần thứ tư đã và đang tác động đến tất cả các lĩnh vực của đời sống xã hội với mức độ khác nhau, mở ra những cơ hội đồng thời cũng đặt ra những thách thức đối với sự phát triển mỗi quốc gia. Trong cuộc cách mạng công nghiệp lần thứ tư, quản trị nhà nước với ý nghĩa thực hiện các quyền lực chính trị để quản lý một quốc gia, quản lý nguồn lực kinh tế và xã hội để thúc đẩy sự thịnh vượng, ổn định và gắn kết xã hội, bảo đảm sự phát triển bền vững có vai trò đặc biệt quan trọng. Quản trị nhà nước giữ vai trò định hướng, điều tiết, hỗ trợ, kiến tạo các điều kiện để phát triển, dự báo và đưa ra những giải pháp giảm tác động tiêu cực của các thách thức của cuộc cách mạng công nghiệp lần thứ tư đối với các chủ thể để bảo đảm sự phát triển ổn định của quốc gia. Để thực hiện tốt vai trò của mình, năng lực quản trị nhà nước cần được nâng tầm, đổi mới toàn diện cả về tư duy, phương thức quản lý. Trong hệ thống các giải pháp nâng cao năng lực quản trị nhà nước thông qua đội ngũ cán bộ, công chức, đào tạo, bồi dưỡng được xem là một giải pháp có ý nghĩa đặc biệt quan trọng.
2. Những thách thức đặt ra trong đào tạo, bồi dưỡng cán bộ, công chức nhìn từ cuộc cách mạng công nghiệp lần thứ tư

Đào tạo, bồi dưỡng cán bộ, công chức về bản chất phải là công cụ phát triển năng lực thực thi công vụ của đội ngũ cán bộ, công chức. Quá trình này giúp cho cán bộ, công chức có năng lực thực thi nhiệm vụ trong hiện tại, đồng thời, có sự chuẩn bị năng lực cho việc đảm nhận những công việc trong tương lai. Trong cuộc cách mạng công nghiệp lần thứ tư, tri thức được sáng tạo nhiều hơn, nhanh hơn và cũng có xu hướng lạc hậu nhanh hơn. Nếu cán bộ, công chức không bổ sung, cập nhật kiến thức, kỹ năng mới đồng nghĩa với "mù chữ". Alvin Toffler từng khẳng định: "Người mù chũ của thế kỷ 21 không phải là người không biết đọc, không biết viết mà là nguoời không biết học hỏi, tùu chối hoc hỏi và tù chối học lại" [3]. Đội ngũ cán bộ, công chức - chủ thể quản trị nhà nước nếu thiếu kiến thức, tri thức của thời đại sẽ không chỉ ảnh hưởng đến công việc của bản thân họ mà còn ảnh hưởng đến năng lực, hiệu lực, hiệu quả quản trị nhà nước. Điều đó có nghĩa là năng lực của đội ngũ cán bộ, công chức sẽ có tác động lớn đến đời sống kinh tế-xã hội.Trong cuộc cách mạng công nghiệp lần thứ tư, để quản trị nhà nước hiệu quả chúng ta cần có đội ngũ cán bộ, công chức ít nhất ở mức 4.0. Đội ngũ cán bộ, công chức phải thực sự là những người tiên phong về năng lực, tư duy và khả năng hành động, phải mang trong mình những phẩm chất của người lao động thời đại cách mạng 4.0. Cán bộ, công chức phải có tinh thần học tập suốt đời, có năng lực tư duy, tầm nhìn, khả năng thích ứng và đưa ra những quyết định hợp lý trên cơ sở khai thác các cơ sở dữ liệu. Với những yêu cầu đối với quản trị nhà nước trong cuộc cách mạng công nghiệp lần thứ tư, hoạt động đào tạo, bồi dưỡng cán bộ, công chức đang đối mặt với những thách thức sau:

Thư nhất, chất lượng đào tạo, bồi dưỡng cán bộ, công chức vẫn chưa đáp ứng được kỳ vọng. Báo cáo Tổng kết thực hiện Chương trình tổng thể cải cách hành chính nhà nước giai đoạn 
2001-2010 và quan điểm, mục tiêu, nội dung cải cách hành chính nhà nước giai đoạn 20112020 đưa nhận xét rất đáng suy ngầm: "Yếu kém lớn nhất là chất luợng của đội ngũ cán bô,, công chức vẫn chura đáp úng được yêu cầu quản lý nhà nước trong co chế móit. Mặc dù công tác đào tạo, bồi dương được tăng cường, số lượng cán bộ, công chức qua các lớp, khoá đào tạo, bồi dương khá lớn, nhưng nhìn chung chất lượng, nhất là kiến thức quản lý nhà nuơờc mới với k̃̃ năng nghiệp vu hành chính thực sư đạt được ở tý lệ thấp. Bà̀ng cấp, chứng chi tăng, nhưng chất lượng về chuyên môn của cán bộ, công chức có bằng cấp, chứng chỉ lại đang là vấn đề đáng lo ngại" [4]. Điều này phần nào cho thấy công tác đào tạo, bồi dưỡng chưa thực sự đem lại hiệu quả như mong đợi, chưa thực sự là công cụ để nâng cao chất lượng đội ngũ cán bộ, công chức, nâng cao năng lực thực thi công vụ. Chính vì vậy, để nâng cao hiệu quả đào tạo, bồi dưỡng, vấn đề đổi mới công tác cán bộ, công chức cần được đặt ra với cách tiếp cận phù hợp hơn.

Thú hai, đào tạo, bồi dưỡng cán bộ, công chức chưa được tiếp cận với tư duy mới trong điều kiện khối lượng tri thức ngày càng gia tăng, đa dạng và phong phú hơn.Tư duy về đào tạo, bồi dưỡng cán bộ, công chức trong những năm qua chưa phản ánh đầy đủ bản chất của đào tạo, bồi dưỡng cán bộ, công chức. Bản chất của quá trình này phải là quá trình phát triển năng lực cho cán bộ, công chức. Vì vậy, việc đào tạo, bồi dưỡng phải xác định những khiếm khuyết, những khoảng trống trong năng lực của cán bộ, công chức đề "lấp đầy", đồng thời, tìm ra những năng lực cần có của cán bộ, công chức trong giai đoạn tiếp theo để xây dựng cho họ thông qua đào tạo, bồi dưỡng, chuẩn bị năng lực cho cán bộ, công chức trước những biến động của môi trường quản lý. Chính vì tư duy đào tạo, bồi dưỡng chưa gắn với phát triển năng lực nên việc thiết kế chương trình, phương thức đào tạo chưa hướng đến bổ sung năng lực và bảo đảm xây dựng năng lực của cán bộ, công chức đáp ứng yêu cầu ngày càng cao của quá trình thực thi công vụ.
Từ tư duy đào tạo, bồi dưỡng chưa gắn với mục tiêu phát triển năng lực nên phương thức đào tạo hiện nay chủ yếu theo chức nghiệp, nhằm đáp ứng tiêu chuẩn ngạch, bậc của công chức, chưa chú trọng đầy đủ tới những kiến thức và kỹ năng để xây dựng cho người công chức năng lực thực hiện tốt hơn công việc và nhiệm vụ được giao. Trong cuộc cách mạng công nghiệp lần thứ tư, các loại hình dịch vụ cần được cá nhân hóa, được tùy biến hóa để thích ứng với từng đối tượng trong khi đó đào tạo, bồi dưỡng cán bộ, công chức vẫn còn tồn tại tư duy đào tạo đại trà cho nhiều nhóm đối tượng khác nhau. Đào tạo, bồi dưỡng chưa chú ý đúng mức đến việc phân tầng, phân loại kiến thức, kỹ năng cho từng nhóm đối tượng. Sự dàn trải về nội dung đào tạo, bồi dưỡng dẫn đến không phải nội dung nào cũng phù hợp với đối tượng đào tạo, bồi dưỡng dẫn đến làm giảm hiệu quả đào tạo. Hiện trạng công tác đào tạo, bồi dưỡng hiện tại đang gây ra tình trạng hẫng hụt về năng lực thực thi, năng lực thích ứng với yêu cầu quản lý và phát triển của đất nước ngay trong giai đoạn trước mắt và nếu nhìn xa hơn trong tương lai nếu hiện trạng này không được cải thiện thì sự hẫng hụt này càng trở thành thách thức lớn đối với năng lực, hiệu quả của nền công vụ.

Tư duy về đào tạo, bồi dưỡng công chức chưa gắn chặt với phát triển năng lực cũng dẫn đến việc đánh giá tác động của đào tạo, bồi dưỡng ít được chú ý hoặc có thực hiện nhưng ít nhiều còn mang tính hình thức. Việc chưa chú ý đến đánh giá tác động đào tạo, bồi dưỡng dẫn đến thiếu cơ sở thực tiễn để đổi mới chương trình, và nội dung giảng dạy. Cái vòng luẩn quẩn đào tạo, bồi dưỡng chưa hiệu quả dẫn đến năng lực làm việc không được cải thiện, sức ép cần đưa đi đào tạo, bồi dưỡng càng tăng lên nhưng đến lượt mình đào tạo, bồi dưỡng chưa trở thành kênh phát triển năng lực thì yêu cầu nâng cao hiệu quả thực thi công vụ càng gặp những trở ngại để được hiện thực hoá.

Thư $b a$, quy trình đào tạo, bồi dưỡng cán bộ, công chức chưa được chú ý thực hiện khoa học. Hoạt động đánh giá nhu cầu đào tạo, bồi dưỡng thường được thực hiện trong phạm vi 
tương đối hẹp, chưa phản ánh đầy đủ nhu cầu đào tạo, bồi dưỡng của cán bộ, công chức, chưa xác định đúng những thiếu hụt về kiến thức, kỹ năng của đội ngũ cán bộ, công chức cần được bổ sung, cập nhật. Chính vì vậy, tình trạng cán bộ, công chức tham gia nhiều khóa tập huấn nhưng vẫn thiếu kiến thức, thiếu kỹ năng làm việc bởi lẽ cán bộ, công chức chưa được học đúng nội dung kiến thức, kỹ năng còn thiếu hụt.Cuộc cách mạng công nghiệp lần thứ tư đang cho thấy cán bộ, công chức cần bổ sung thêm nhiều kiến thức và kỹ năng mới, có khả năng thích ứng, dám thích ứng và biết thích ứng với yêu cầu quản trị nhà nước ở giai đoạn mới. Cán bộ, công chức cần có tư duy tổng hợp, khả năng khai thác các tiện ích công nghệ, hệ thống cơ sở dữ liệu để đưa ra các quyết định quản lý tối ưu.

\section{3. Định hướng đổi mới đào tạo, bồi dưỡng cán bộ, công chức tromg bối cảnh cuộc cách mạng công nghiệp lần thứ tư}

Trước hết, cần thay đổi nhận thức về đào tạo, bồi dưỡng cán bộ, công chức. Đào tạo, bồi dưỡng là quá trình phát triển năng lực với mục tiêu để nâng cao năng lực thực thi công vụ của cán bộ, công chức. Việc đánh giá kết quả đào tạo, bồi dưỡng cán bộ, công chức không nên và không thể dừng lại ở số lượng như: tổ chức được bao nhiêu khóa đào tạo, bao nhiêu đối tượng học viên tham gia các khóa đào tạo, bồi dưỡng mà điều căn bản là cán bộ, công chức có những thay đổi như thế nào, có những sự phát triển nào trong năng lực thực thi công vụ, trong thái độ phục vụ tổ chức và công dân. Nói cách khác, đào tạo, bồi dưỡng cán bộ, công chức phải hướng đến mục tiêu, đến hiệu quả làm việc sau quá trình đào tạo, bồi dưỡng của cán bộ, công chức.

Thú hai, đổi mới chương trình đào tạo, bồi dưỡng cán bộ, công chức. Các chương trình, tài liệu đào tạo, bồi dưỡng được cập nhật thường xuyên hơn và có sự điều chỉnh cho phù hợp với từng nhóm đối tượng học viên. Quá trình xây dựng chương trình, tài liệu đào tạo, bồi dưỡng cần phải nâng cao tính tương tác giữa cơ sở đào tạo với cơ quan quản lý, sử dụng cán bộ, công chức, với chính cán bộ, công chức để xác định chính xác những thiếu hụt trong năng lực thực thi công vụ của họ. Cần bảo đảm chương trình, tài liệu đào tạo, bồi dưỡng cập nhật được các kiến thức mà cán bộ, công chức cần biết, phải biết và nên biết. Đồng thời, các cơ sở đào tạo cần phải xác định được những tri thức nào mà cán bộ, công chức cần phải có để thực thi nhiệm vụ tốt hơn trong tương lai từ đó cập nhật, bổ sung, cung cấp những cẩm nang hướng dẫn cho cán bộ, công chức trong quá trình thực thi công vụ.

Quá trình xây dựng chương trình, tài liệu đào tạo, bồi dưỡng cần mở rộng sự tham gia, bảo đảm tập hợp được tri thức liên ngành, đa ngành và cập nhật để chương trình, tài liệu không phải là những gì mà cơ sở đào tạo, bồi dưỡng có mà phải là những tri thức mà nền công vụ và cán bộ, công chức thực sự cần.

Thứ $b a$, nâng cao chất lượng đội ngũ giảng viên.Các cơ sở đào tạo, bồi dưỡng công chức cần có cơ chế cho giảng viên đi thực tế với thời gian từ 3-6 tháng ở các địa phương, các bộ ngành để có thông tin thực tiễn, phục vụ cho việc giảng dạy. Đồng thời, các cơ sở đào tạo, bồi dưỡng cần xây dựng đội ngũ giảng viên kiêm chức tham gia các khoá bồi dưỡng theo vị trí việc làm. Ở nhiều nước trên thế giới, các cơ sở đào tạo, bồi dưỡng đóng vai trò là người tổ chức còn giảng viên là những chuyên gia, các nhà quản lý có nhiều kinh nghiệm thực tiễn. Trên thực tế, những người có kinh nghiệm trong việc thực hiện những công việc đó mới biết được và chỉ dẫn cụ thể được phải làm việc đó như thế nào và làm sao để đạt hiệu quả cao nhất. Kinh nghiệm quốc tế chỉ ra rằng phát triển đội ngũ giảng viên kiêm chức sẽ có được một đội ngũ giảng viên đủ về số lượng, có bề dầy kinh nghiệm quản lý và công tác thực tiễn.

Bên cạnh kiến thức chuyên môn, kinh nghiệm thực tiê̂n, đội ngũ này cần được bồi dưỡng về nghiệp vụ sư phạm. Các cơ sở đào tạo, bồi dưỡng công chức rất khác biệt với các trường đại học, cao đẳng nên không thể chỉ mời sinh viên giỏi mới tốt nghiệp đại học để giảng 
dạy, mà nên tìm kiếm những nhà quản lý giỏi, những công chức giỏi (cả về lý thuyết và thực hành) trong lĩnh vực làm việc của họ để làm giảng viên kiêm chức.

Thư tux, đổi mới phương thức đào tạo, bồi dưỡng cán bộ, công chức. Đào tạo trực tuyến thông qua lớp học ảo, mô phỏng, số hóa bài giảng cần là xu hướng đào tạo, bồi dưỡng cán bộ, công chức trong tương lai gần. Đào tạo, bồi dưỡng cán bộ, công chức ngày càng đòi hỏi tính chuyên sâu về nhằm nâng cao kiển thức, phát triển kỹ năng, rèn luyện thái độ công vụ phù hợp. Nội dung đào tạo, bồi dưỡngkhông ngừng tăng lên khối lượng kiến thức, kỹ năng. Điều này mâu thuẫn với những rào cản về không gian và thời gian đối với cả giảng viên và học viên. Đào tạo, bồi dưỡng cán bộ, công chức trực tuyến chính là chìa khóa quan trọng để giải quyết mâu thuẫn đó.

Đào tạo trực tuyến là hoạt động đào tạo hiện đại, ứng dụng những thành tựu của phát triển của khoa học, công nghệ (thành tựu của cuộc cách mạng công nghiệp lần thứ tư), phù hợp với các quốc gia có diện tích rộng lớn, các cơ quan nhà nước trải dài trên vùng lãnh thổ rộng lớn. Đào tạo trực tuyến thường có hiệu quả cao gấp nhiều lần so với đào tạo thông thường do: Học viên có thái độ và động lực tốt hơn do họ hoàn toàn tự nguyện tham gia hoạt động đào tạo; Do phải thiết kế bài giảng và thực hiện video nên giảng viên sẽ chuẩn bị chu đáo, nghiêm túc hơn.

Đào tạo, bồi dưỡng cán bộ, công chức trực tuyến tăng cường cơ hội tiếp cận giữa học viên với các giảng viên có năng lực. Nếu như đào tạo, bồi dưỡng cán bộ, công chức truyền thống, các giảng viên giỏi chỉ có thể đào tạo, bồi dưỡng cho một nhóm nhỏ cán bộ, công chức tham gia các khóa đào tạo, bồi dưỡng thì đào tạo cán bộ, công chức trực tuyến, bài giảng của giảng viên này sẽ được đưa đến với số lượng học viên lớn hơn. Với việc áp dụng công nghệ thông tin và truyền thông vào đào tạo, bồi dưỡng cán bộ, công chức, đào tạo, bồi dưỡng trực tuyến cho phép tăng cường số lượng cán bộ, công chức được đào tạo, bồi dưỡng mà không cần đầu tư mở rộng số lượng phòng học. Giới han về số lượng về lớp trong một khóa đào tạo, bồi dưỡng ở phương pháp đào tạo, bồi dưỡng cán bộ, công chức truyền thống được khắc phục triệt để thông qua phương pháp đào tạo, bồi dưỡng cán bộ, công chức trực tuyến. Điều này cũng giúp cho đào tạo trực tuyến có chi phí thấp hơn do giảm chi phí đi lại, tiền giảng và thời gian cho cả giảng viên và người học.

Thư năm, tăng cường hợp tác quốc tế trong đào tạo, bồi dưỡng cán bộ, công chức. Mục tiêu, yêu cầu của hợp tác quốc tế về đào tạo, bồi dưỡng cán bộ, công chức trong giai đoạn hiện nay là nghiên cứu tiếp thu, áp dụng các mô hình hiệu quả trong đào tạo, bồi dưỡng công chức phù hợp với thực tiễn Việt Nam. Việc hợp tác quốc tế cũng tạo ra áp lực để đổi mới công tác đào tạo, bồi dưỡng công chức ở nước ta. Các biện pháp chủ yếu để thực hiện những mục tiêu đặt ra là nghiên cứu áp dụng mô hình đào tạo, bồi dưỡng công vụ; xây dựng những chương trình hợp tác quốc tế ngắn hạn và dài hạn theo chỉ tiêu kinh phí Nhà nước đồng thời lồng ghép nội dung đào tạo, bồi dưỡng công chức vào các dự án do nước ngoài tài trợ với nhiều hình thức phong phú, đa dạng, như gửi các đoàn đi đào tạo ở nước ngoài, tồ chức đào tạo, bồi dưỡng ở trong nước với sự trợ giúp của các chuyên gia nước ngoài hoặc trong và ngoài nước kết hợp.

\section{Tài liệu tham khảo}

[1] Klaus Schwab, The fourth industrial revolution, 2017.

[2] World Economic Forum, The future of job, 2016.

[3] Alvil Tofler, Thăng trầm quyền lực, NXB. Thông tin lý luận, 1991.

[4] Báo cáo Tổng kết thực hiện Chương trình tổng thể cải cách hành chính nhà nước giai đoạn 2001-2010. 


\title{
Training of Cadres and Civil Servants in the Context of the Fourth Industrial Revolution
}

\author{
Hoang Mai \\ National Academy of Public Administration, No 77, Nguyen Chi Thanh, Dong Da, Hanoi, Vietnam
}

\begin{abstract}
In the context of the Fourth Industrial Revolution, State governance capacity should be improved to ensure adaptability. This requires training for cadres and civil servants to be innovated and developed in order to truly be the tool for developing their capacity. Therefore, the practices of training for cadres and civil servants shall be essentially renovated in both of the contents of training programs and the methods in organizing training activities. That guarantees the cadres and civil servants will have their capacities intrinsically improved in line with state manangement requirement in the new period. In this article, analysis are conducted to explore the challenges that the Fourth Industrial Revolution may impose on training of cadres and civil servants; and recommendations on renovating training of cadres and civil servants are also raised.
\end{abstract}

Keywords: Training, cadres, civil servants; the Fourth Industrial Revolution. 